\section{Category}

Chemistry in

Medicine and

Biology

\section{Key words}

\section{azithromycin}

Beckmann

rearrangement

antibiotic

SARS-CoV-2

S. DJOKIĆ, G. KOBREHEL, G. LAZAREVSKI*, N. LOPOTAR, Z. TAMBURAŠEV, B. KAMENAR, A. NAGL, I. VICKOVIĆ (PLIVA, ZAGREB, CROATIA)

Erythromycin Series. Part 11. Ring Expansion of Erythromycin A Oxime by the Beckmann Rearrangement J. Chem. Soc., Perkin Trans. 1 1986, 1881-1890.

\title{
Azithromycin - An Antibiotic to Fight COVID-19?
}

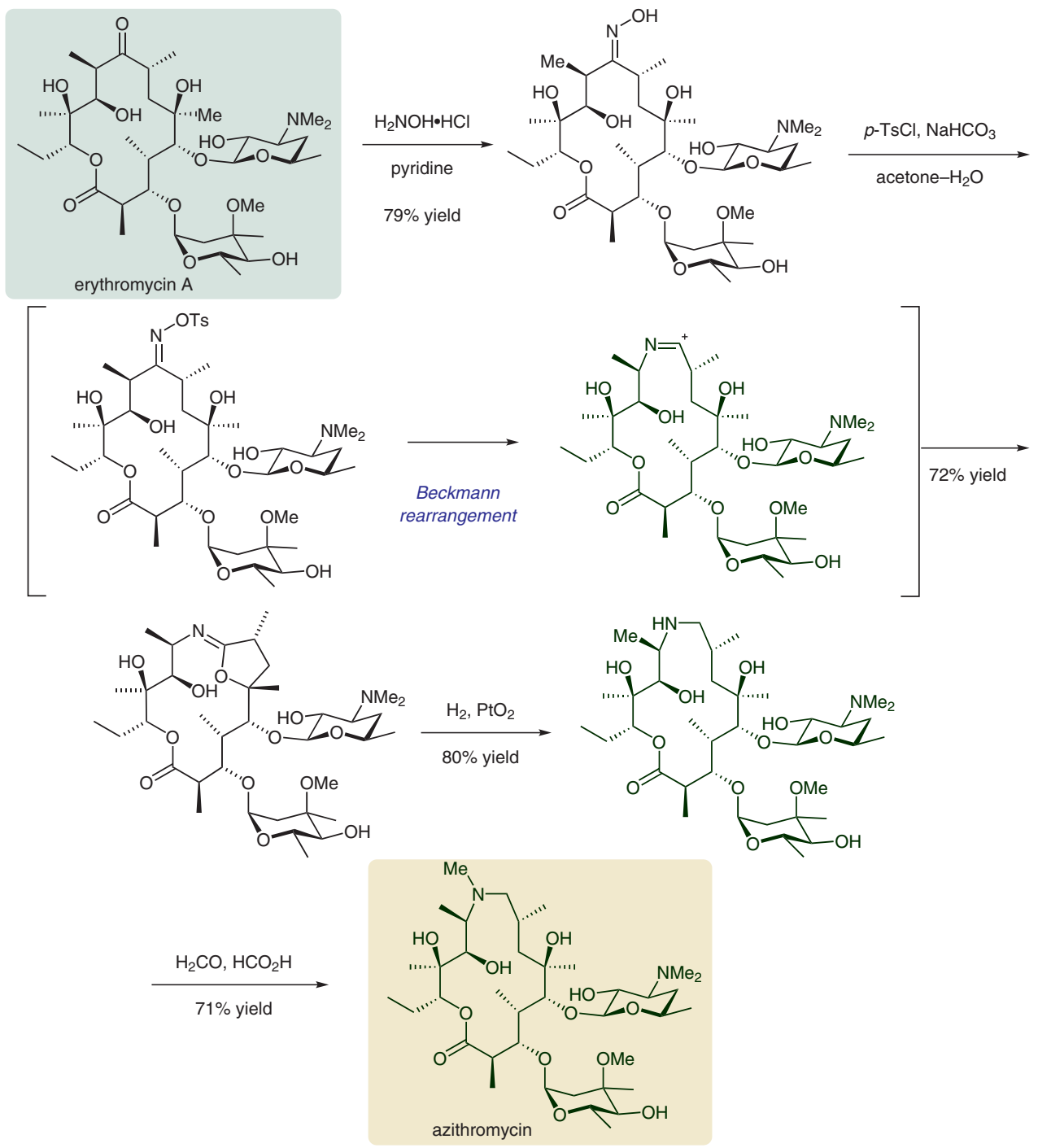

Significance: Macrolide antibiotics can be used for the treatment of a wide variety of bacterial infections. Unfortunately, the acid lability of the natural product itself, erythromycin A, results in side effects of nausea and stomach-ache. Djokić et al. overcame this problem by replacing the C9 carbonyl group with an amine functionality. Azithromycin has been used successfully as an antibiotic for many years and recently showed promising effects in a combination treatment with chloroquine to fight COVID-19.
Comment: The semisynthesis of azithromycin was accomplished within a four-step sequence from erythromycin A. Beckmann rearrangement of the O-tosyl oxime afforded a cyclic imino ether intermediate, which, after hydrogenation, yielded the ring-expanded 15-membered heterocycle. Methylation (J. Chem. Res. Synop. 1988, 152) of the secondary amine afforded azithromycin. 